\title{
Effect of dry period length on reproduction during the subsequent lactation
}

\author{
R. D. Watters, M. C. Wiltbank, ${ }^{1}$ J. N. Guenther, A. E. Brickner, R. R. Rastani, P. M. Fricke, and R. R. Grummer \\ Department of Dairy Science, University of Wisconsin, Madison 53706
}

\begin{abstract}
Days dry may influence reproductive measures such as days to first postpartum ovulation, days open, and pregnancy per artificial insemination (AI). Holstein cows $(\mathrm{n}=781)$ from an approximately 3,000-cow commercial dairy operation were randomly assigned to 1 of 2 treatments with different targeted dry period (DP) lengths. Treatments were 1) a traditional DP of $55 \mathrm{~d}$ (T) or 2) a shortened DP of $34 \mathrm{~d}(\mathrm{~S})$. All dry cows on $\mathrm{T}$ were fed a low-energy diet until $35 \mathrm{~d}$ before expected calving, and then at $34 \mathrm{~d}$ before expected calving, cows on $\mathrm{T}$ and $\mathrm{S}$ were fed a moderate energy diet until parturition. After parturition, all cows consumed the same diets that included a postcalving diet followed by a lactation diet. Actual days dry for each treatment were close to expected values, 34 and $56 \mathrm{~d}$ for $\mathrm{S}$ and $\mathrm{T}$, respectively. Median days until first postpartum ovulation occurred sooner for S compared with T (35 vs. 43 d). The percentage of cows that were classified anovular by $70 \mathrm{~d}$ in milk (DIM) was more than 2 -fold greater for cows on $\mathrm{T}$ than $\mathrm{S}$ (18 vs. 8\%). Cows received AI after standing estrus starting at $\mathrm{d} 45$, and the percentage of cows pregnant at 70 DIM tended to be greater for $\mathrm{S}$ than T; younger cows were similar (20.2 vs. $18.8 \%$ ), but there was a difference between $\mathrm{S}$ and $\mathrm{T}$ in older cows (20.3 vs. $10.6 \%$ ). Similarly, median days open tended to be fewer for cows on S than T. At 300 DIM, $85 \%$ of cows in both treatments were pregnant. Combining data from first and second service, pregnancies per AI were greater in older cows on S than T (32 vs. 24\%). Thus, shortening the DP appeared to increase reproductive efficiency in older cows by shortening time to first ovulation, reducing numbers of anovular cows, and improving fertility. Future studies at more locations with varying reproductive management strategies are needed to confirm and provide the mechanistic basis for these results.
\end{abstract}

Key words: dry period length, reproduction, first postpartum ovulation

Received April 23, 2008.

Accepted January 19, 2009.

${ }^{1}$ Corresponding author: wiltbank@wisc.edu

\section{INTRODUCTION}

Evaluation of optimal dry period (DP) length has previously been based upon milk production, but animal health and reproductive performance may need consideration in making this decision. There is limited research on the effect of DP length on reproduction. We have speculated that length of the DP may influence postpartum energy balance (EB), potentially altering reproductive performance.

There is a relationship between EB and first postpartum ovulation (Butler et al., 1981; Canfield et al., 1990). Butler et al. (1981) theorized that the EB nadir was important for determining first postpartum ovulation and resumption of cyclicity. First postpartum ovulation occurred between 10 and $14 \mathrm{~d}$ after the EB nadir was reached (Butler et al., 1981; Canfield et al., 1990). Rastani et al. (2005) reported that cows receiving no DP or a reduced DP (28 d) had less negative EB compared with cows on a traditional 56-d DP. Consistent with the relationship between EB and days to first postpartum ovulation, Gümen et al. (2005) found that cows with shorter DP ovulated sooner $(13.2,23.8$, and $31.9 \mathrm{~d}$ for $0-, 28-$, and 56-d DP, respectively). Reproductive performance of dairy cattle improved with earlier return to cyclicity (Thatcher and Wilcox, 1973; Darwash et al., 1997; Staples et al., 1990); however, some studies reported lower (Smith and Wallace, 1998) or no change (Royal et al., 2000) in reproductive performance with shorter time to first ovulation. Consistent with the concept that earlier first ovulation may improve reproductive performance, decreasing DP length was associated with an increased percentage of cows pregnant to first AI $(55,26$, and $20 \%$ for $0-, 28-$, and 56-d DP, respectively) and decreased days open $(94,121$, and $145 \mathrm{~d}$ for 0-, 28-, and 56-d DP, respectively; Gümen et al., 2005). Nevertheless, these authors clearly stated that their intensive study was not done with a sufficient number of cows ( $\mathrm{n}=66$ in 3 treatment groups) to allow valid evaluation of DP length on economically important measures of reproductive efficiency. In another recent study (Pezeshki et al., 2007), reproductive measures were altered by varying DP length. Days open was somewhat lower in cows with a 56-d DP than with a 42 -d DP, but first-service conception rate was greater in multiparous 
cows with a 35-d DP vs. longer DP. Still, most of the differences in reproductive measures did not reach statistical significance because of inadequate replication ( $\mathrm{n}=108$ cows divided into 3 treatment groups). Thus, the present study was designed to evaluate the effect of DP length on milk production, health events (both reported in Watters et al., 2008), and reproductive values. This report presents the effects on reproductive traits. The study was done on a large commercial dairy to provide a sufficient number of cows to validly analyze economically important reproductive measures. Measures of reproductive performance included 1) days to first postpartum ovulation, 2) days to first AI, 3) days to pregnancy, and 4) pregnancies per AI (P/AI). We hypothesized that cows with a shorter DP would have decreased days to first postpartum ovulation, as shown in the previous study (Gümen et al., 2005), and would have improved reproductive performance, particularly earlier pregnancy. All data were analyzed separately for younger (first-lactation cows approaching their second lactation) and older (cows approaching their third or greater lactation) cows because of previous data indicating differences in the effect of DP length on milk production of cows of different parities (Kuhn et al., 2006; Pezeshki et al., 2007; Watters et al., 2008).

\section{MATERIALS AND METHODS}

\section{Cows and Treatments}

Details of the experimental protocol along with milk production and health results were provided previously (Watters et al., 2008). Briefly, 781 Holstein cows from a commercial dairy herd with approximately 3,000 lactating cows were enrolled. At $170 \mathrm{~d}$ of gestation, cows were assigned randomly to 1 of 2 DP strategies: 1) a traditional 55-d DP (T) or 2) a shortened DP of $34 \mathrm{~d}$ (S). Before assigning, the following conditions had to be met at $170 \mathrm{~d}$ of gestation: 1) milk production needed to be $\geq 18 \mathrm{~kg} / \mathrm{d}$, and 2) cows had to be $<400$ DIM. A total of 417 first-lactation cows and 355 cows in their second or greater lactation were assigned. Bovine somatotropin was used, according to label directions, on cows in both treatments during the experiment based on visual inspection of BCS by the herd manager, who did not have knowledge of treatment groups.

All cows were fed a TMR prepartum and postpartum. Diets differed between groups from 55 to $35 \mathrm{~d}$ before expected calving: cows on $\mathrm{T}$ were fed a lowenergy ( $\mathbf{L E})$ diet and cows on $\mathrm{S}$ were fed a lactation diet because they were still being milked. From $34 \mathrm{~d}$ before expected calving through the end of the trial, cows on both treatments were fed the same diet and kept in the same pens. Diets were balanced to meet the requirements of nonlactating cows or to meet or exceed the requirements for lactating cows (NRC, 2001).

Cows were milked 3 times daily except from parturition through 30 DIM when they were milked 4 times daily. Determination of BCS on all cows was done weekly by a single individual starting at $3 \mathrm{wk}$ before expected calving and continuing until $10 \mathrm{wk}$ postpartum. A scale of 1 (very thin) to 5 (obese) was used to score each cow using quarter point increments (Wildman et al., 1982). The University of Wisconsin-Madison, College of Agriculture and Life Sciences, Animal Care and Use Committee approved the experimental protocol.

\section{Blood Sampling and Analysis}

The postpartum interval to the commencement of luteal activity was determined from blood samples used to analyze progesterone concentration. Blood samples for progesterone analysis were collected once weekly at approximately $0900 \mathrm{~h}$ from the coccygeal vein into Vacutainer tubes (Becton Dickinson Co., Franklin Lakes, NJ). Serum was subsequently separated by centrifugation, collected, and stored at $-20^{\circ} \mathrm{C}$ until analysis for progesterone. Blood sampling for progesterone analysis began $14 \mathrm{~d}$ after parturition. The first serum sample with a progesterone concentration $>1 \mathrm{ng} / \mathrm{mL}$ was designated as the day of first ovulation. Blood sampling continued weekly until a progesterone concentration above $1 \mathrm{ng} / \mathrm{mL}$ was measured or until 70 DIM was reached.

Solid-phase RIA kits with antibody-coated tubes and ${ }^{125}$ I-labeled progesterone (Coat-A-Count, Diagnostic Products Corp., Los Angeles, CA) were utilized to determine serum progesterone concentrations (Gümen and Wiltbank, 2005). A quality control of pooled bovine serum $($ mean $=1.03 \pm 0.06 \mathrm{ng} / \mathrm{mL})$ was evaluated in all assays. The interassay coefficient of variation was $6.3 \%$.

\section{Reproductive Status}

Beginning at 4 DIM, the reproductive tracts of all cows were palpated for uterine health, and this continued every other day until 14 DIM. Additionally, all cows received a routine veterinarian examination at 21 DIM including palpation of the reproductive tract. There were no other reproductive examinations performed until a planned pregnancy diagnosis at approximately 35 d post-AI. Cows without ovulation detected before 70 DIM were considered anovular. Percentage of cows pregnant to first AI was determined by the number of pregnant cows divided by the number of inseminations. This same procedure was used to determine percentage of cows pregnant to second service and to all services. 


\section{Detection of Estrus and Al}

Cows in both experimental groups were commingled with the rest of the cows in the herd without identification of treatment group. All cows received the reproductive management protocol that was routinely utilized on the herd, which included a 45-d voluntary waiting period (VWP), application of tail chalk, and daily observation for detection of estrus after VWP, routine use of 1 straw of semen to breed 2 cows, and initiation of the Ovsynch protocol (Pursley et al., 1995) on one day of the week in cows that were nonpregnant and $\geq 70$ DIM. A Cosynch-72 protocol was utilized (100 $\mu \mathrm{g}$ of $\mathrm{GnRH}$; at $7 \mathrm{~d}, 25 \mathrm{mg}$ of $\mathrm{PGF}_{2 \alpha} ; 3 \mathrm{~d}$ later, $100 \mu \mathrm{g}$ of $\mathrm{GnRH}+\mathrm{AI})$. Thus, all cows not detected in estrus during the early postpartum period received their first AI between 80 and 86 DIM.

\section{Statistical Analysis}

The LIFETEST procedure (SAS Institute, 1999) was used to perform survival analysis of time-dependent binomial data, including days dry, days open, and time to first ovulation, first AI, and pregnancy. Differences in time-dependent data were analyzed by Kaplan-Meier survival curve estimation. The nonparametric test of 2 samples obtained from survival analysis were tested for homogeneity by the Wilcoxon homogeneity test (Wilcoxon, 1945). Survival curves for time to second and third AI were determined using only cows that were eligible (nonpregnant) after first or second AI, respectively. Any cow that did not ovulate by 70 DIM was assigned a censored value of $70 \mathrm{~d}$ for survival analysis of days to first ovulation.

Data for pregnancy status were analyzed using the PROC FREQ option (SAS Institute, 1999). The chisquare statistic was used to determine differences between treatment groups in the days to first ovulation, days to first AI, and percentage of cows pregnant at various DIM (i.e., 150 DIM) and percentage of cows P/ AI. Significant differences were declared at $P<0.05$ for main effects and interactions, and a tendency was declared at $0.05 \leq P<0.1$. For determination of time intervals with significant differences between treatments, data were analyzed at 5- to 10 -d intervals, and differences were indicated directly on survival curve graphs.

\section{RESULTS}

The actual days dry were similar to planned days dry with median values of 34 and $56 \mathrm{~d}$ for cows on $\mathrm{S}$ and $\mathrm{T}$, respectively. The survival curves for days dry in both treatment groups had a steep slope near the median,

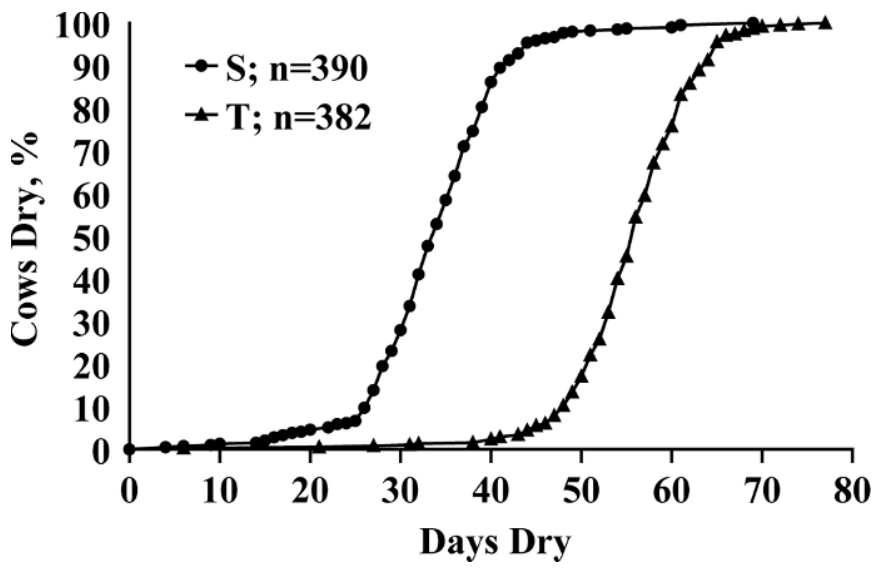

Figure 1. Survival curves of days dry for cows managed for shortened (S) 34-d ( ) or traditional (T) 55-d ( $\mathbf{\Delta}$ ) dry period.

indicative of actual DP lengths close to planned DP (Figure 1). More than $90 \%$ of S cows had a DP length between 20 and $45 \mathrm{~d}$, whereas $>90 \%$ of $\mathrm{T}$ cows had a DP length between 44 and $65 \mathrm{~d}$.

Gestation length did not differ between T and S (275.8 \pm 1.2 vs. $274.3 \pm 0.8 \mathrm{~d}$, respectively; $P=0.29$ ). There was no treatment $\times$ parity or treatment $\times$ pregnancy status (pregnant with single or twin fetuses) interaction for gestation length, although cows carrying twins had a gestation length approximately $5 \mathrm{~d}$ shorter than cows with singletons (277.5 vs. $272.7 \mathrm{~d} ; P=0.001)$. There were 35 twin calvings during the experiment with no differences between treatments.

Time to ovulation was based on analysis of weekly progesterone concentrations with an increase $>1 \mathrm{ng} /$ $\mathrm{mL}$ designated as date of ovulation. Analysis of all cows (Figure 2A) showed that there were some early ovulating cows, with $3.9 \%$ of $\mathrm{T}$ and $6.2 \%$ of $\mathrm{S}$ having increased progesterone by 20 DIM. From 20 to 40 DIM, the increase in cows ovulating had a consistent slope of 2.8 and $2.1 \% / \mathrm{d}$ for $\mathrm{S}$ and $\mathrm{T}$, respectively (slopes not statistically compared), resulting in a greater percentage of cows cycling in $\mathrm{S}$ than $\mathrm{T}$ at 40 DIM $(62.7$ vs. $45.8 \% ; P=0.001)$. First ovulations continued from 40 to 70 DIM although at a somewhat reduced rate $(\mathrm{T}=1.21 \% / \mathrm{d} ; \mathrm{S}=0.98 \% / \mathrm{d})$. At $70 \mathrm{DIM}$, analysis of all cows indicated that there were more than twice as many anovular cows in $\mathrm{T}$ than $\mathrm{S}(18$ vs. $8 \% ; P=$ 0.002 ). Overall analysis of the survival curves indicated that cows in $\mathrm{S}$ ovulated earlier than cows in $\mathrm{T}(34.0 \pm$ 0.40 vs. $55.8 \pm 0.36 \mathrm{~d} ; P=0.02)$.

Analysis of only the younger cows (second lactation) for days to first ovulation indicated a trend similar to the results with all cows (Figure 2B). Younger cows on $\mathrm{S}$ had earlier first ovulation, starting at 30 to 50 DIM, than cows on T. Overall analysis of the survival curve 


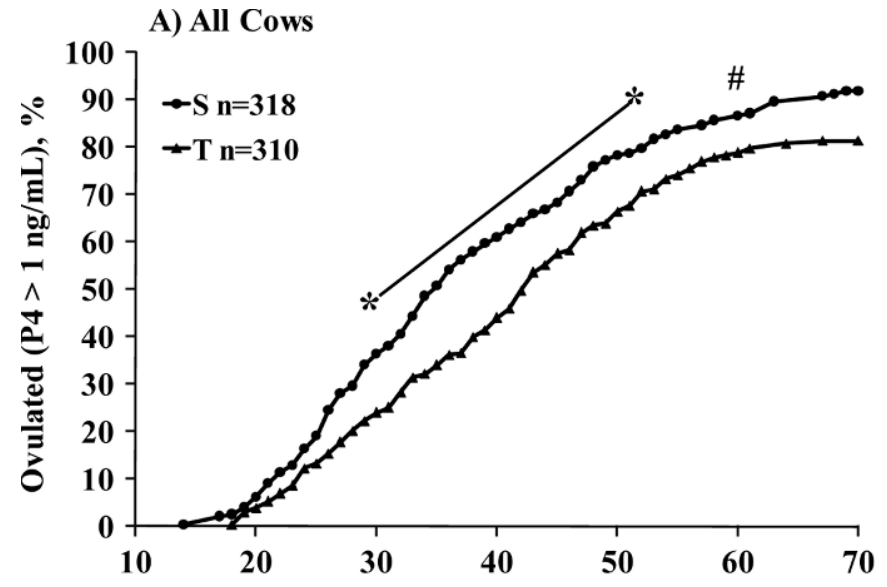

B) Second Lactation Cows

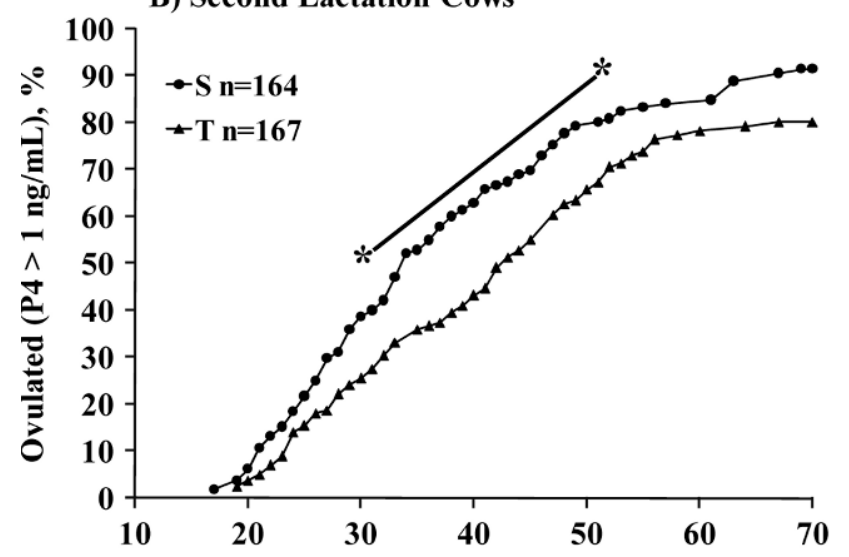

C) Older Cows

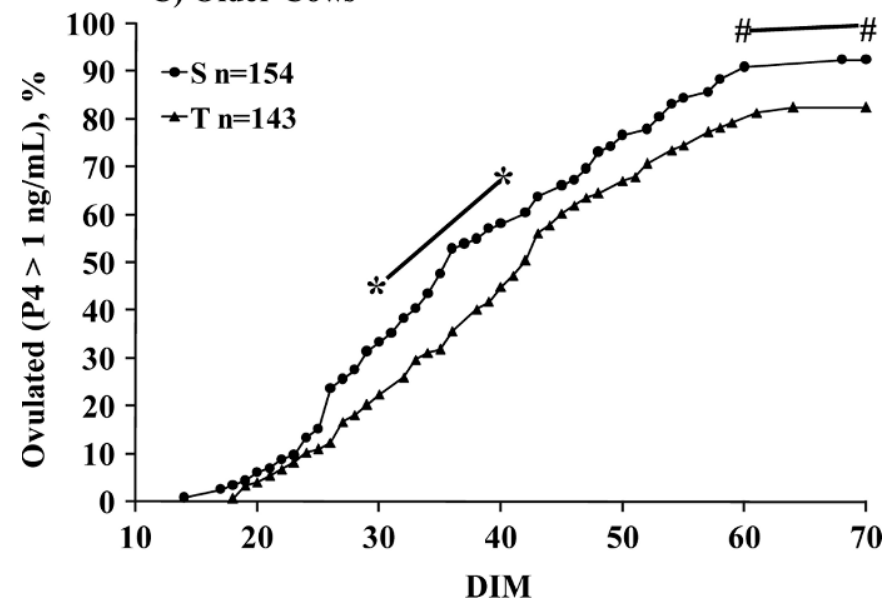

Figure 2. Survival curves for days to first ovulation for cows managed for shortened 34-d $(\bullet, S)$ or traditional 55-d $(\boldsymbol{\Delta}, \mathrm{T})$ dry period shown for A) all cows; B) younger cows (dry period between first and second lactation and reproduction during second lactation); and C) older cows in $\geq$ third lactation. Differences between treatment groups were analyzed at 10-d intervals by chi-square analysis and significant differences are shown directly on the Kaplan-Meier curves; $*$ indicates $P<0.05$, and \# indicates $0.05 \leq P<0.1$, with lines connecting points with similar statistical differences. $\mathrm{P} 4=$ progesterone. indicated that younger cows had earlier days to first ovulation after $\mathrm{S}$ than $\mathrm{T}$ (median of 34 vs. $43 \mathrm{~d} ; P<$ 0.002 ).

Similarly, older cows ( $\geq$ third lactation) had earlier time to first ovulation in $\mathrm{S}$ than $\mathrm{T}$, with statistical differences detected by 30 DIM (Figure 2C). Overall analysis of the survival curve for older cows indicated earlier time to first ovulation in $\mathrm{S}$ than $\mathrm{T}$ (median of 36 vs. $42 \mathrm{~d} ; P=0.02$ ). There was no effect of parity on time to first ovulation. For example, for $\mathrm{T}$ there was a similar percentage of cows that had ovulated by 40 DIM (parity $2=45.1 \%$ vs. parity $3+=46.6 \%$ ) or 60 DIM (parity $2=82.0 \%$ vs. parity $3+=85.3 \%$ ).

Cows in both groups began AI starting after the VWP of 45 DIM (Figure 3A). The overall rate for detection of estrus during the 25 -d time period from 45 to 70 DIM was moderate, with $42.5 \%$ of eligible cows receiving first AI before 70 DIM. Overall, cows in S tended to receive $\mathrm{AI}$ at an earlier time than cows in $\mathrm{T}$ (67 vs. 73 d; $P=0.07$. At initiation of Ovsynch (70 DIM) there was a higher percentage of cows that had received AI in S than T (46.4 vs. $38.3 \%$; $P=0.03$ ). Because of the timed AI, essentially all cows had received first AI by 86 DIM. Both the second-lactation cows (Figure 3B) and the older cows (Figure 3C) showed similar trends. Parity (lactation number) had little effect on days to first AI for cows in either S or T. The days to second AI were similar between treatments $(\mathrm{S}=102.5$ vs. $\mathrm{T}=105$ $\mathrm{d} ; P=0.18)$ and for parity 2 vs. parity $3+$ (Table 1 ).

Cows began to become pregnant starting after the VWP of 45 DIM (Figure 4A). Before Ovsynch treatment (before $70 \mathrm{DIM}$ ), there tended to be more $\mathrm{S}$ than T cows pregnant at 70 DIM $[18.8 \%(67 / 358)$ vs. $15.0 \%$ $(52 / 346) ; P=0.07$ ] for all cows (Figure 4A). Similarly at $150 \mathrm{DIM}$, the percentage of animals pregnant tended to be greater for $\mathrm{S}$ than $\mathrm{T}$ cows (61 vs. $54 \% ; P=$ 0.08; Figure 4A). The percentage of animals that were pregnant by 300 DIM did not differ between treatments $(\mathrm{S}=84.4$ vs. $\mathrm{T}=85.1 \%)$. Days open tended to be lower for $\mathrm{S}$ than $\mathrm{T}$ when cows of all parities were analyzed (median of 110 vs. $127 \mathrm{~d} ; P=0.09$ ).

Analysis of the time to pregnancy in younger cows (Figure 4B) did not indicate any effect of treatment. For example, at 70 DIM there were similar percentages of $\mathrm{S}$ and $\mathrm{T}$ cows pregnant $(\mathrm{S}=20.2 \%$ vs. $\mathrm{T}=18.8 \%$; $P=0.73)$. Similarly, at $150 \mathrm{DIM}, \mathrm{S}$ and $\mathrm{T}$ cows had similar percentage of pregnant cows $(\mathrm{S}=64$ vs. $\mathrm{T}=$ $61 \%$; Table 1 ). The median days open were not different for younger $\mathrm{S}$ and $\mathrm{T}$ cows $(\mathrm{S}=109$ vs. $\mathrm{T}=121 \mathrm{~d}$; $P=0.65)$.

For older cows, there were differences in time to pregnancy between treatments (Figure 4C). Before Ovsynch, S cows became pregnant at a faster rate than 

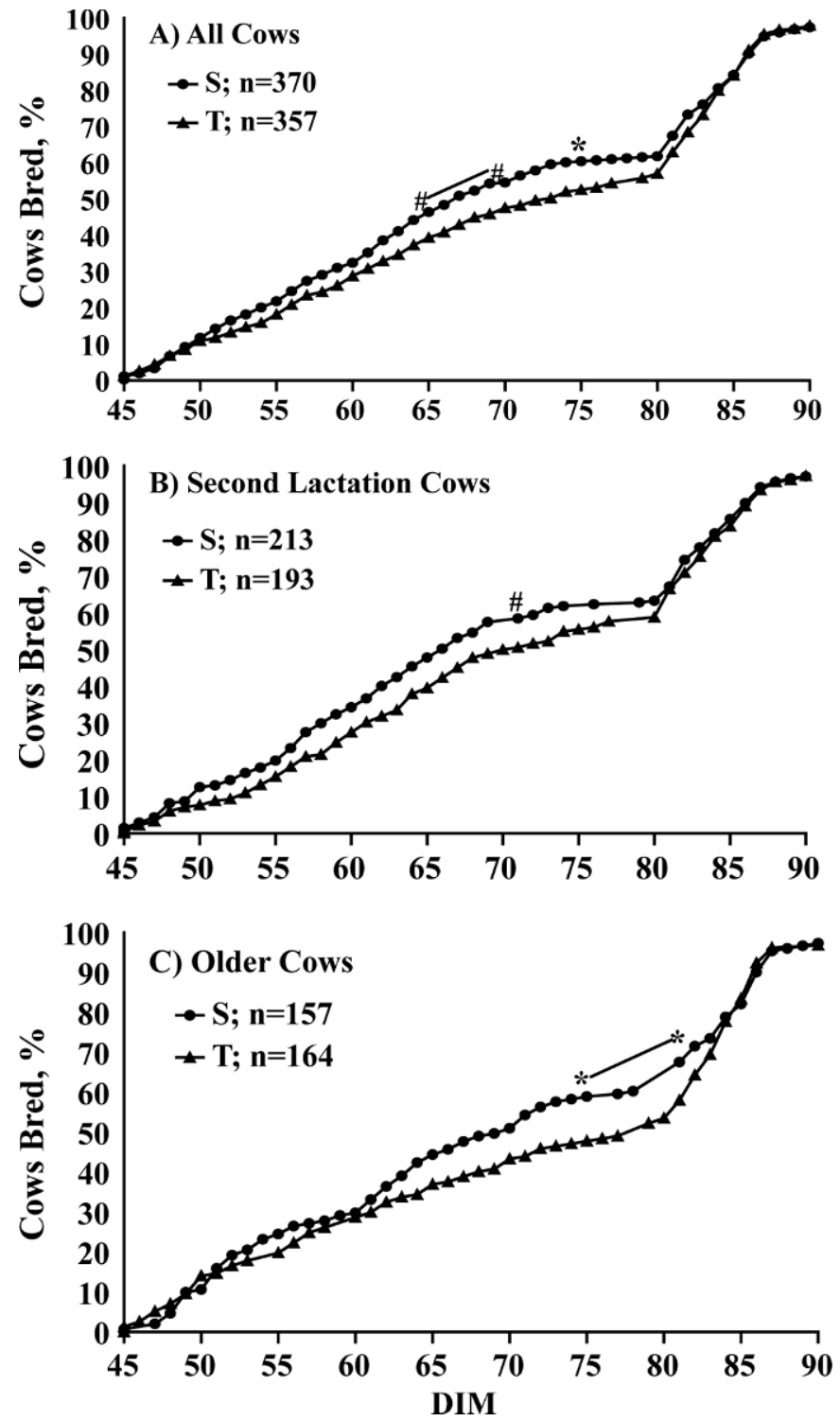

Figure 3. Survival curve for days to first AI for cows managed for shortened $(\bullet$, S) 34-d dry period or traditional $(\boldsymbol{\Lambda}, \mathrm{T})$ 55-d dry period shown for A) all cows; B) younger cows (dry period between first and second lactation and reproduction during second lactation); and $\mathrm{C}$ ) older cows in $>$ third lactation. Differences between treatment groups were analyzed at 5 -d intervals by chi-square analysis and significant differences are shown directly on the Kaplan-Meier curves; $*$ indicates $P<0.05$, and \# indicates $0.05 \leq P<0.1$, with lines connecting points with similar statistical differences.

$\mathrm{T}$ cows (pregnancies produced per day between 50 and 70 DIM: $\mathrm{S}=0.73 \% / \mathrm{d}$ vs. $\mathrm{T}=0.32 \% / \mathrm{d})$. Thus, by 70 DIM a greater percentage of $\mathrm{S}$ than $\mathrm{T}$ cows was pregnant (20.3 vs. $10.6 \% ; P=0.02)$. At 110 DIM there was a greater percentage of $\mathrm{S}$ than $\mathrm{T}$ cows pregnant (49.3 vs. $38.0 \% ; P<0.05$ ). At 150 DIM, there were no statistical differences between groups ( $\mathrm{S}=61 \%$ vs. $\mathrm{T}$ $=54 \%, P=0.14)$. The days open tended $(P=0.06)$ to be less for $\mathrm{S}$ than $\mathrm{T}$ cows (113 vs. $133 \mathrm{~d}$ ).
Overall, $\mathrm{P} / \mathrm{AI}$ did not differ between cows on $\mathrm{S}$ vs. $\mathrm{T}$ at first service $[\mathrm{S}=31.9 \%(114 / 357)$ vs. $\mathrm{T}=30.3 \%$ $(103 / 340) ; P=0.64)$, but tended to differ at second service $[\mathrm{S}=32.3 \%(75 / 232)$ vs. $\mathrm{T}=24.5 \%(54 / 220)$; $P=0.07$; Table 1]. Nevertheless, there were no statistically significant differences in $\mathrm{P} / \mathrm{AI}$ in parity 2 cows at first service, second service, or the combination of first and second service. The older cows had a somewhat similar but nonsignificant effect of treatment on $\mathrm{P} / \mathrm{AI}$ at both first and second service. Combining data from first and second AI resulted in statistically lower P/AI for T than S (24.3 vs. $32.0 \% ; P=0.05)$ in older cows. Combining data for all inseminations done on the cows throughout the experiment resulted in no difference in $\mathrm{P} / \mathrm{AI}$ between the groups in either younger $[\mathrm{S}=30.7 \%$ $(161 / 524)$ vs. $\mathrm{T}=32.4 \%(150 / 463) ; P=0.57]$ or older cows $[\mathrm{S}=31.0 \%(123 / 397)$ vs. $\mathrm{T}=26.7 \%(112 / 420)$; $P=0.17]$.

As outlined above, cows received AI after a detected estrus until $70 \mathrm{~d}$ postpartum with subsequent timed AI in this herd. Therefore, we chose to analyze key intervals that might provide some insight into the effect of DP length on specific components of this reproductive management program. The 3 chosen intervals were 1 ) the time period before Ovsynch treatments (45 to 69 DIM), 2) the time period including the first Ovsynch treatment (70 to $89 \mathrm{DIM}$ ), and 3 ) the time period after the first Ovsynch, but before the second Ovsynch treatment (90 to 109 DIM). During these 3 intervals, an analysis was performed on the effect of DP length on key measures of reproductive efficiency: 1) heat detection rate (\% of eligible cows receiving $\mathrm{AI}$ during the chosen interval); 2) fertility (\% $\mathrm{P} / \mathrm{AI}$ of AI during the chosen interval); and 3) pregnancy rate (\% of eligible cows that became pregnant during the chosen interval). Comparisons were done only within an interval because the intervals differed in length (Table 2). Because parity differences were found by survival analyses, reproductive analyses during these intervals were performed for parity 2 cows separately from cows of parity $\geq 3$ (parity $3+$; Table 3).

During the first interval (45 to $69 \mathrm{~d}$ ) there was a greater percentage of cows receiving $\mathrm{AI}$ in $\mathrm{S}$ than $\mathrm{T}$ (54 vs. $45 \% ; P=0.02$; Table 2 ). There was no difference in fertility ( $\mathrm{S}=35 \%$ vs. $\mathrm{T}=33 \%$ ), resulting in a tendency for a greater pregnancy rate in $\mathrm{S}$ during this early period ( $\mathrm{S}=19 \%$ vs. $\mathrm{T}=15 \% ; P=0.09$ ). During this time interval there was a numerically greater percentage of $\mathrm{S}$ than $\mathrm{T}$ cows being bred for both parity 2 and $3+$ (Table 3 ). There was a tendency for greater $\mathrm{P} / \mathrm{AI}$ in parity $3+$ cows during this early interval ( $\mathrm{S}$ $=39 \%$ vs. $\mathrm{T}=25 \% ; P=0.07)$, resulting in a greater pregnancy rate for $\mathrm{S}$ than $\mathrm{T}$ cows in parity $3+$ during this early interval (19 vs. $10 \% ; P=0.02)$. 
Table 1. Differences in reproductive measures after cows were targeted for a shortened (S) 34-d or a traditional (T) 55-d dry period for younger (parity 2) or older (parity $3+$ ) cows

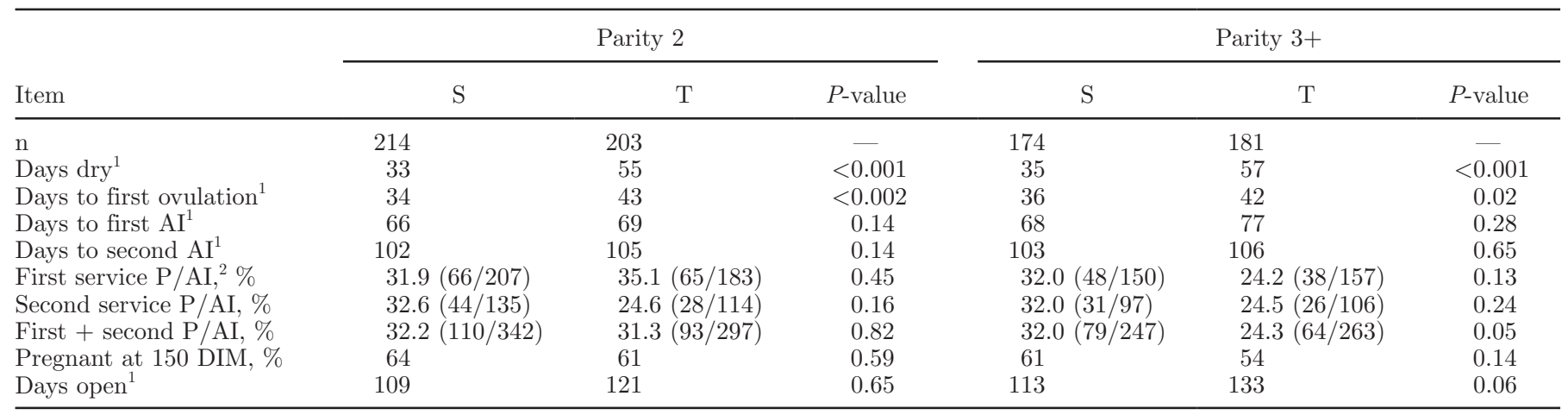

${ }^{1}$ Values are from survival analysis with medians listed.

${ }^{2} \mathrm{P} / \mathrm{AI}=$ pregnancies per $\mathrm{AI}$.

In contrast, the second time interval (70 to 89 DIM including Ovsynch timed AI; Table 2) had similar percentage of cows that received $\mathrm{AI}$ in $\mathrm{S}$ and $\mathrm{T}(\mathrm{S}=73$ vs. $\mathrm{T}=77 \%$ ). There was no difference in $\mathrm{P} / \mathrm{AI}$ during this period ( $\mathrm{S}=32 \%$ vs. $\mathrm{T}=30 \%$ ). This resulted in an equivalent pregnancy rate $(23 \%)$ for $\mathrm{S}$ and $\mathrm{T}$ during this 20-d period. A lack of difference in reproduction during this time interval was observed in cows of parity 2 and parity $3+$ (Table 3 ).

The third interval represented another time when cows received AI after estrus (90 to 109 DIM, after first Ovsynch and before second Ovsynch; Table 2). There tended to be a greater percentage of $\mathrm{S}$ cows receiving AI ( 45 vs. $37 \%, P=0.15 ; \mathrm{P} / \mathrm{AI}$ for $\mathrm{S}=36 \%$ vs. $\mathrm{T}=$ $27 \%, P=0.20)$. This resulted in a greater pregnancy rate in $\mathrm{S}$ than $\mathrm{T}$ (16 vs. $10 \%$; $P=0.05$ ) during this time interval. These differences were found in spite of no differences between $\mathrm{S}$ and $\mathrm{T}$ cows for reproduction during this time interval in both parity 2 and $3+$ (Table 3 ).

\section{DISCUSSION}

This study was designed to test the effect of DP length on reproduction in lactating dairy cows on a commercial dairy. We hypothesized that reducing the DP length would result in better reproductive efficiency, as observed in a recent study (Gümen et al., 2005) that did not have sufficient numbers of cows per treatment group to provide valid results on reproductive traits of economic importance. The present study was designed with almost 400 cows assigned per treatment group to provide more valid information on the binomial outcomes (e.g., fertility, anovulation) that are critical for determining the success of reproductive programs. This study provided substantial novel information on the effect of DP length on reproduction in dairy cattle, although some key reproductive traits still provided only tendencies for statistical differences, even with much larger treatment groups. Our current results showed a reduction in days to first ovulation after cows had a shorter DP than with a traditional 55-d DP length. One of the most important observations was the tendency for a reduction in days to pregnancy when cows had a shorter DP length. Surprisingly, improvement in time to pregnancy was only observed in older cows (second lactation or more) and not younger cows (cows going from first to second lactation). There was a tendency for approximately a $20-\mathrm{d}$ improvement in time to pregnancy in the older cows that had a shorter DP compared with a traditional DP length. Similarly, in our previous smaller study (Gümen et al., 2005) there was a reduction in days open of $24 \mathrm{~d}$ when cows had a shortened (28-d) vs. a traditional (56-d) DP. This contrasts with the results of Pezeshki et al. (2007) who reported lower days open in cows with a traditional (56-d) DP than cows on shorter DP.

The median interval to first postpartum ovulation was less for cows on $\mathrm{S}$ than $\mathrm{T}$ (35 vs. $43 \mathrm{~d}$ ) and this difference was observed in both younger and older cows (Table 1). The observation of earlier ovulation in cows with a shorter DP was consistent with the results of Gümen et al. (2005) who reported that days to first postpartum ovulation was $23.8 \mathrm{~d}$ for cows with a 28 -d DP compared with 31.9 d for cows with a 56-d DP length. Although the difference between groups $(\sim 8 \mathrm{~d})$ is almost identical in both studies, cows in the previous study appeared to have somewhat earlier ovulation in all treatment groups. Earlier observation of first ovulation would be expected in the previous study because of more frequent evaluation of cows for first ovulation (3 times weekly vs. once weekly) and due to use of ultrasound evaluation of the ovaries. Shortening the DP to $0 \mathrm{~d}$ (no planned DP) resulted in a further reduction in time to first ovulation (13.2 d; Gümen et al., 2005). 

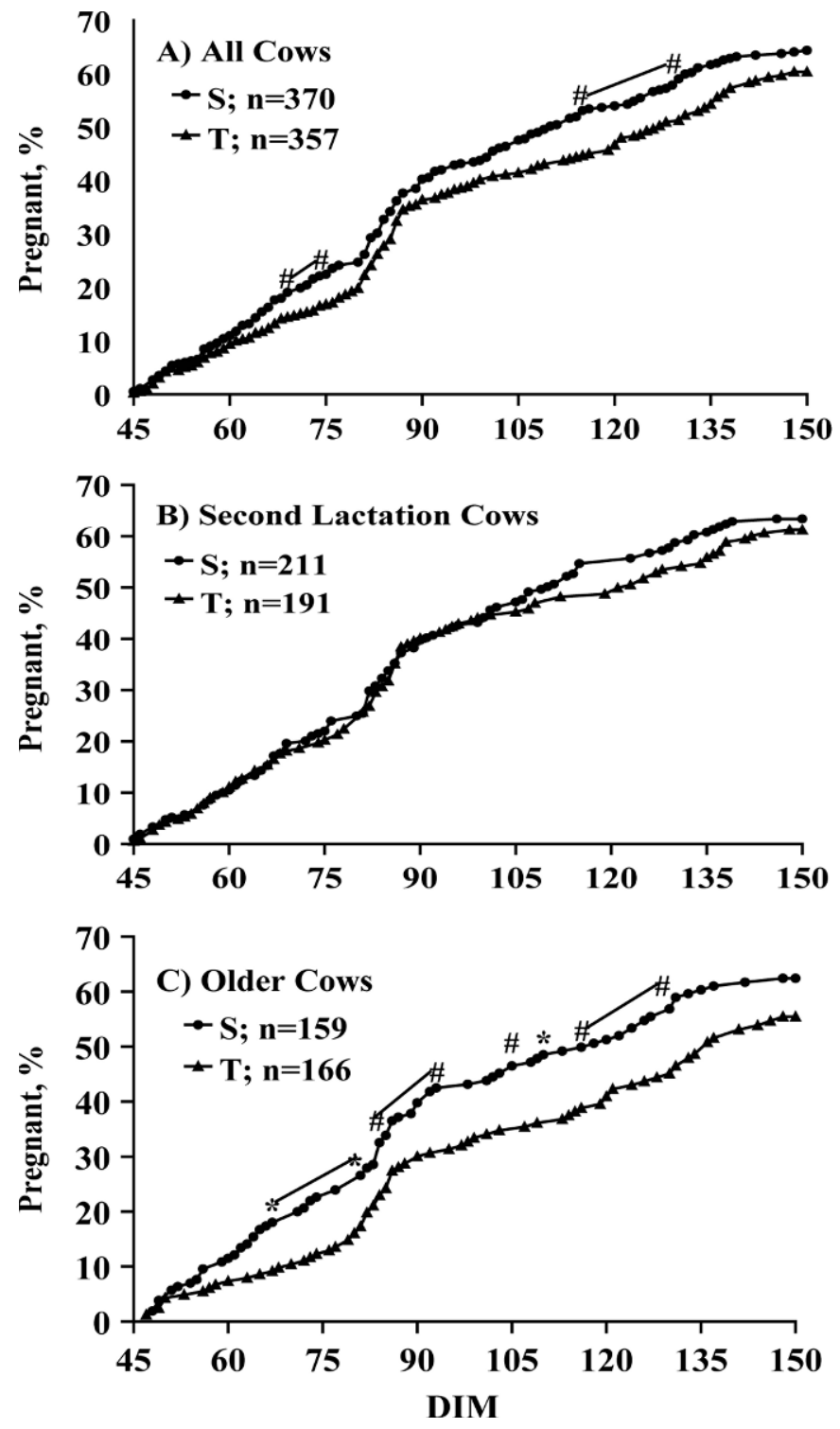

Figure 4. Survival curve for days to pregnancy with data truncated at 150 DIM for cows managed for shortened 34-d $(\bullet, S)$ or traditional 55-d $(\boldsymbol{\Lambda}, \mathrm{T})$ dry period shown for A) all cows; B) younger cows (dry period between first and second lactation and reproduction during second lactation); and C) older cows in $\geq$ third lactation. Differences between treatment groups were analyzed at 5 -d intervals by chi-square analysis and significant differences are shown directly on the KaplanMeier curves; ${ }^{*}$ indicates $P<0.05$, and \# indicates $0.05 \leq P<0.1$, with lines connecting points with similar statistical differences.

Shorter DP and earlier ovulation were associated with a reduction in negative $\mathrm{EB}$ during the first $3 \mathrm{wk}$ after calving $(1.7 \pm 1.2,-6.3 \pm 0.9$, and $-9.6 \pm 0.6 \mathrm{Mcal} / \mathrm{d}$ for 0,28 , and $56 \mathrm{~d} \mathrm{DP}$; unpublished data from further analysis of results of Rastani et al., 2005). A more positive EB was primarily related to increased DMI in cows with shorter DP (Rastani et al., 2005). This reduction in negative EB after a shorter DP likely accounts for the earlier postpartum ovulation and reduction in anovular cows by 70 DIM. Many (Butler et al., 1981; Beam and Butler, 1998), but not all (Lucy et al., 1992,) previous data are consistent with earlier ovulation in cows with less negative EB during the postpartum period. Although a few cows may ovulate as early as $10 \mathrm{~d}$ postpartum (Butler et al., 1981), the average time to first ovulation is near $30 \mathrm{~d}$ in older (Butler et al., 1981) and more recent studies (Spicer et al., 1990; Zurek et al., 1995; Sakaguchi et al., 2004). Our results are consistent with these times to first ovulation.

Based on our previous results, we hypothesized that fewer days to first ovulation in cows with shortened DP would result in earlier time to pregnancy (Grummer, 2007). There is considerable evidence that increasing numbers of estrous cycles before breeding are correlated with a decrease in services per pregnancy, indicating that earlier onset of first ovulation may increase reproductive efficiency (Thatcher and Wilcox, 1973; Lucy et al., 1992; Darwash et al., 1997). Indeed, Darwash et al. (1997) reported that increasing days to first postpartum ovulation reduced fertility and increased days to pregnancy. Similarly, Lucy et al. (1992) observed that when first ovulation occurred before 42 DIM, services per pregnancy were less than if it occurred after 42 DIM. In contrast, Smith and Wallace (1998) reported that ovulation before 21 DIM was associated with reduced pregnancy rates, increased services per pregnancy, and a prolonged calving to pregnancy interval for multiparous, but not primiparous dairy cows. In our results, both younger and older cows had fewer days to first ovulation in response to a shorter DP length. Still, only the older cows had earlier time to pregnancy. The observation that younger cows had shorter time to first ovulation but no improvement in time to pregnancy is somewhat inconsistent with the earlier time to first ovulation being the underlying mechanism causing earlier pregnancy in cows with shorter DP. In addition, although changes in BCS affected fertility (Butler and Smith, 1989; Garnsworthy and Webb, 1999), the differences in BCS between $\mathrm{S}$ and $\mathrm{T}$ in this study were minor (Watters et al., 2008) and may not have been the primary cause of changes in reproduction. Nonetheless, the 3 -wk postpartum NEFA concentrations were significantly lower for $\mathrm{S}$ than $\mathrm{T}$ cows (Watters et al., 2008) and this may reflect a more favorable EB. It seems clear that further research is needed to define the relationships between fertility, endocrine measures, metabolic measures, and first ovulation, particularly as altered by different DP lengths.

In this study, the improved reproductive efficiency after a shorter DP was observed early during the breeding period in the older cows. For example, by 69 DIM there was an increased percentage of older cows preg- 


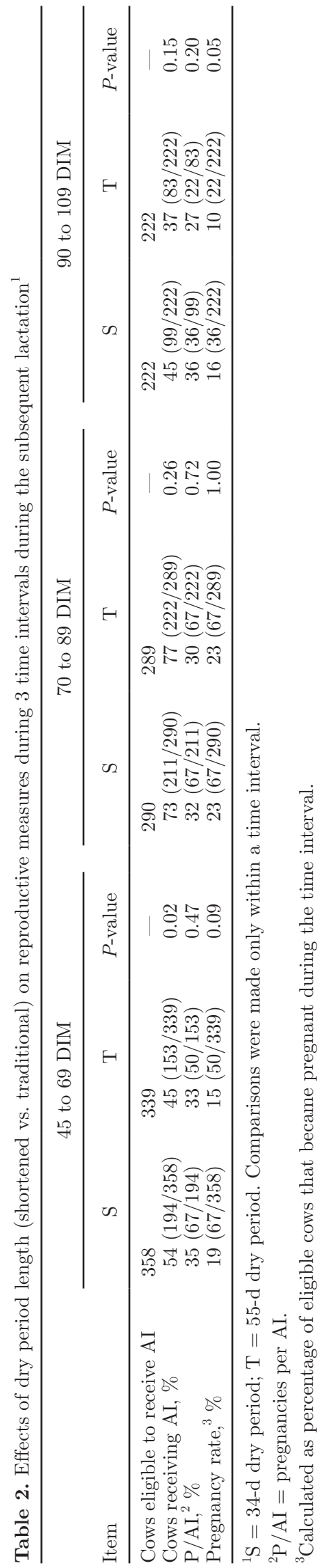

nant with the shorter DP. This improvement in fertility continued during the first 150 DIM, but diminished as lactation lengthened (Figure 4). Gümen et al. (2005) reported that days open were reduced when DP was shortened (93.8, 121.2, and $145.4 \mathrm{~d}$ for 0-, 28-, and 56-d DP, respectively). Nevertheless, Lotan and Adler (1976) found that the number of services, pregnancy rate, and days open did not differ when comparing 30- to 60-d DP. Similarly, Pezeshki et al. (2007) did not find a consistent improvement in reproductive measures with decreased DP length, although first-service conception rate was higher in multiparous cows with a 35-d DP compared with a $42-$ or 56 -d DP.

The improvement in days to pregnancy could be related to earlier postpartum $\mathrm{AI}$, improved $\mathrm{P} / \mathrm{AI}$, or some combination of improved $\mathrm{P} / \mathrm{AI}$ and time to AI. The data in Figure 3 and Table 2 indicate that a higher percentage of cows with a shorter DP had an earlier time to first detected estrus, and a higher percentage of cows received AI after observed estrus before the timed AI than for cows with a longer DP. For example, $54 \%$ of $\mathrm{S}$ cows received AI before 69 DIM (when Ovsynch began) compared with only $45 \%$ of $\mathrm{T}$ cows (Table 2 ). This could be due to earlier postpartum ovulation, although better expression of estrus may be important in earlier time to first AI. One possible explanation could be that cows with lower milk production have increased duration of estrus (Lopez et al., 2004); however, this seems unlikely given that older cows on $\mathrm{S}$ and $\mathrm{T}$ had similar milk production during this study (Watters et al., 2008). The use of timed AI appeared to reduce the differences caused by the DP treatment (Figures 3 and 4). It is possible that herds that use only timed AI may observe little benefit from reduced DP lengths; however, this idea was obviously not tested in the present study. Thus, earlier postpartum AI may be responsible for some of the improvement in time to pregnancy. One puzzling inconsistency with this idea is that younger cows had some improvement in time to first ovulation and AI without the improvement in time to pregnancy (Table 1).

There were some results consistent with the idea that improved fertility may be important in the decreased time to pregnancy. There was an improvement of $\sim 8 \%$ (32 vs. 24\%) in absolute value for $\mathrm{P} / \mathrm{AI}$ in older cows in $\mathrm{S}$ compared with $\mathrm{T}$ when analyzing first and second services (Table 1). Gümen et al. (2005) reported that as DP length decreased, there was an increase in first-service fertility $(55,26$, and $20 \%$ for $0-, 28-$, and 56-d DP, respectively). The best first-service conception rates $(53 \%)$ were observed in multiparous cows with the shortest DP in a recent study (Pezeshki et al., 2007). Thus, both earlier postpartum AI and greater 
Table 3. Effects of dry period length (shortened vs. traditional) on reproductive measures during 3 time intervals during the subsequent lactation in parity 2 or parity $3+$ cows $^{1}$

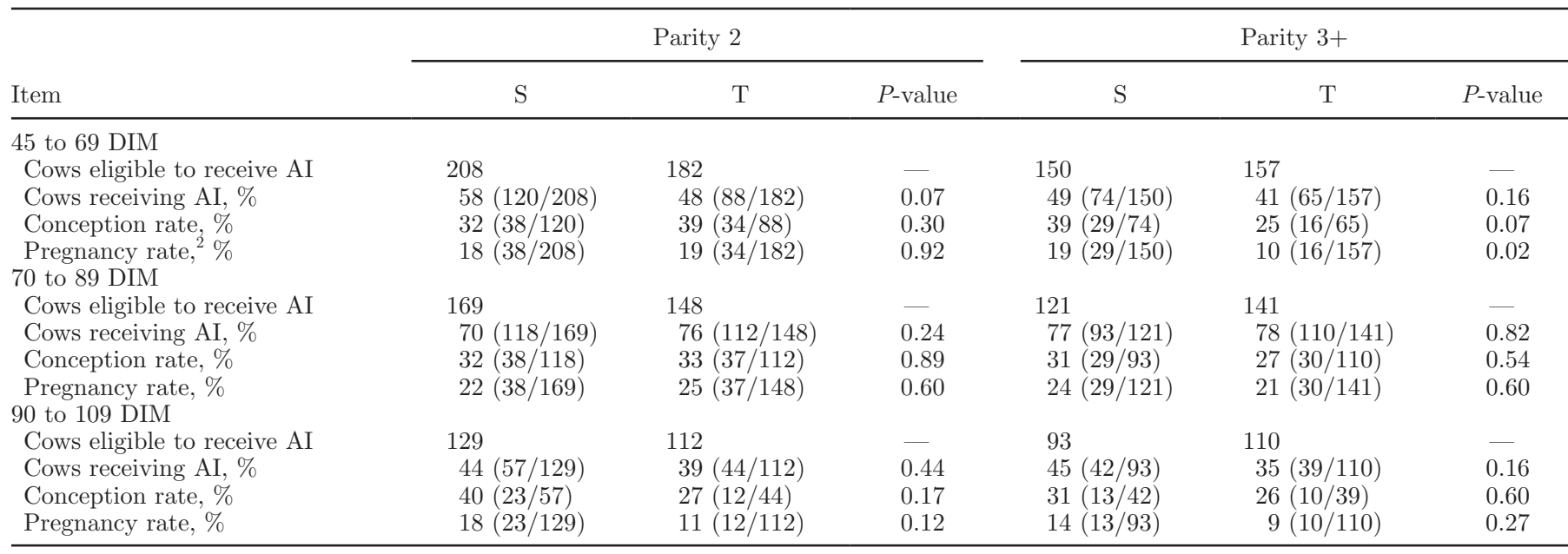

${ }^{1} \mathrm{~S}=34$-d dry period; $\mathrm{T}=55$-d dry period. Comparisons were made only within a time interval.

${ }^{2}$ Calculated as percentage of eligible cows that became pregnant during the time interval.

fertility may be important to produce an earlier time to pregnancy in older cows with a shortened DP.

\section{CONCLUSIONS}

Decreasing reproductive efficiency in dairy herds has become an important economic concern. Improvements in reproductive efficiency lead to increased profit per cow and improved overall efficiency in dairy operations. The results show that when DP is reduced by 22 $\mathrm{d}$, cows ovulated about $8 \mathrm{~d}$ earlier. In addition, there was a reduction in days to pregnancy of about $20 \mathrm{~d}$ in older cows that had a shortened DP. This improvement in reproduction appeared to involve a combination of improved time to first AI and increased fertility at first and second AI. These improvements may be related to the improved EB in cows with shorter DP, although it is puzzling that younger cows showed the reduction in days to first ovulation, but no improvement in time to pregnancy. Nevertheless, this study is consistent with a limited amount of previous data indicating an improvement in reproductive performance of Holstein dairy cattle when DP length was reduced. Future studies are needed with perhaps even larger numbers of cows and herds to further investigate the intriguing relationship between DP length and dairy cattle fertility. Studies should continue to focus on the interaction between parity and DP length in terms of production and reproductive measures.

\section{ACKNOWLEDGMENTS}

We would like to thank Hubbard Feeds Inc. (Mankato, MN), MSC Specialty Nutrition (Dundee, IL), Monsanto
Dairy Business (St. Louis, MO), Pioneer Hi-Bred International Inc. (Johnson, IA), Vita Plus Corp. (Madison, WI), and West Central (Ralston, IA) for their financial support and guidance during the experiment. Special thanks to Peter Crump and Nick Keuler of the University of Wisconsin-Madison for their statistical support. Finally, thanks to Kenn Buelow, Jackie Schnackel, Dennis Zweber, and Chris Ditter for their help and support at Holsum Dairies LLC.

\section{REFERENCES}

Beam, S. W., and W. R. Butler. 1998. Energy balance, metabolic hormones, and early postpartum follicular development in dairy cows fed prilled lipid. J. Dairy Sci. 81:121-131.

Butler, W. R., R. W. Everett, and C. E. Coppock. 1981. The relationships between energy balance, milk production and ovulation in postpartum Holstein cows. J. Anim. Sci. 53:742748

Butler, W. R., and R. D. Smith. 1989. Interrelationships between energy balance and postpartum reproductive function in dairy cattle. J. Dairy Sci. 72:767-783.

Canfield, R. W., C. J. Sniffen, and W. R. Butler. 1990. Effects of excess degradable protein on postpartum reproduction and energy balance in dairy cattle. J. Dairy Sci. 73:2342-2349.

Darwash, A. O., G. E. Lamming, and J. A. Woolliams. 1997. The phenotypic association between the interval to post-partum ovulation and traditional measures of fertility in dairy cattle. Anim. Sci. 65:9-16.

Garnsworthy, P. C., and R. Webb. 1999. The influence of nutrition on fertility in dairy cows. Pages 39-57 in Recent Advances in Animal Nutrition. P. C. Garnsworthy and J. Wiseman, ed. Nottingham University Press, Nottingham, UK.

Grummer, R. R. 2007. Strategies to improve fertility of high yielding dairy farms: Management of the dry period. Theriogenology 68S(Suppl. 1):S281-S288.

Gümen, A., R. R. Rastani, R. R. Grummer, and M. C. Wiltbank. 2005. Reduced dry periods and varying prepartum diets alter postpartum ovulation and reproductive measures. J. Dairy Sci. $88: 2401-2411$ 
Gümen, A., and M. C. Wiltbank. 2005. Length of progesterone exposure needed to resolve large follicle anovular condition in dairy cows. Theriogenology 63:202-218.

Kuhn, M. T., J. L. Hutchison, and H. D. Norman. 2006. Effects of dry period length on yields of milk fat and protein, fertility and milk somatic cell score in the subsequent lactation of dairy cows. J. Dairy Res. 73:154-162.

Lopez, H., L. D. Satter, and M. C. Wiltbank. 2004. Relationship betwen level of milk production and estrous behavior of lactating dairy cows. Anim. Reprod. Sci. 81:209-223.

Lotan, E., and J. H. Adler. 1976. Observations on the effect of shortening the dry period on milk yield, body weight, and circulating glucose and FFA levels in dairy cows. Tijdschr. Diergeneeskd. 101:7782 .

Lucy, M. C., C. R. Staples, W. W. Thatcher, P. S. Erickson, R. M. Cleale, J. L. Firkins, J. H. Clark, M. R. Murphy, and B. O. Brodie. 1992. Influence of diet composition, dry matter intake, milk production and energy balance on time of postpartum ovulation and fertility in dairy cows. Anim. Prod. 54:323-331.

NRC. 2001. Nutrient Requirements of Dairy Cattle. 7th ed. Natl. Acad. Press, Washington, DC.

Pezeshki, A., J. Mehrzad, G. R. Ghorbani, H. R. Rahmani, R. J. Collier, and C. Burvenich. 2007. Effects of short dry periods on performance and metabolic status in Holstein dairy cows. J. Dairy Sci. 90:5531-5541.

Pursley, J. R., M. O. Mee, and M. C. Wiltbank. 1995. Synchronization of ovulation in dairy cows using $\mathrm{PGF}_{2 \alpha}$ and GnRH. Theriogenology 44:915-923.

Rastani, R. R., R. R. Grummer, S. J. Bertics, A. Gümen, M. C. Wiltbank, D. G. Mashek, and M. C. Schwab. 2005. Reducing dry period length to simplify feeding transition cows: Milk production, energy balance, and metabolic profiles. J. Dairy Sci. 88:10041014.

Royal, M. D., A. O. Darwash, A. P. E. Flint, R. Webb, J. A. Woolliams, and G. E. Lamming. 2000. Declining fertility in dairy cattle: Changes in traditional and endocrine parameters of fertility. Anim. Sci. 70:487-501.

Sakaguchi, M., Y. Sasamoto, T. Suzuki, Y. Takahashi, and Y. Yamada. 2004. Postpartum ovarian follicular dynamics and estrous activity in lactating dairy cows. J. Dairy Sci. 87:2114-2121.

SAS Institute. 1999. User's Guide: Statistics. Version 8 ed. SAS Institute, Cary, NC.

Smith, M. C. A., and J. M. Wallace. 1998. Influence of early post partum ovulation on the re-establishment of pregnancy in multiparous and primiparous dairy cattle. Reprod. Fertil. Dev. 10:207-216.

Spicer, L. J., W. B. Tucker, and G. D. Adams. 1990. Insulin-like growth factor-I in dairy cows. Relationships among energy balance, body condition, ovarian activity, and estrous behavior. J. Dairy Sci. 73:929-937.

Staples, C. R., W. W. Thatcher, and J. H. Clark. 1990. Relationship between ovarian activity and energy status during the early postpartum period of high producing dairy cows. J. Dairy Sci. 73:938-947.

Thatcher, W. W., and C. J. Wilcox. 1973. Postpartum estrus as an indicator of reproductive status in dairy cows. J. Dairy Sci. 56:608-610.

Watters, R. D., J. N. Guenther, A. E. Brickner, R. R. Rastani, P. M. Crump, P. W. Clark, and R. R. Grummer. 2008. Effects of dry period length on milk production and health of dairy cattle. J. Dairy Sci. 91:2595-2603.

Wilcoxon, F. 1945. Individual comparison by ranking methods. Biometrics 1:80-83.

Wildman, E. E., G. M. Jones, P. E. Wagner, R. L. Boman, H. F. Troutt Jr., and T. N. Lesch. 1982. A dairy cow body condition scoring system and its relation to selected production characteristics. J. Dairy Sci. 65:495-501.

Zurek, E., G. R. Foxcroft, and J. J. Kennelly. 1995. Metabolic status and interval to first ovulation in postpartum dairy cows. J. Dairy Sci. 78:1909-1920. 